Original Research Paper

\title{
Dynamic Mechanical Properties of Fused Deposition Modelling Processed Polyphenylsulfone Material
}

\author{
${ }^{1}$ Bolin Huang, ${ }^{1}$ S.H. Masood, ${ }^{1}$ Mostafa Nikzad, \\ ${ }^{2}$ Prabhu Raja Venugopal and ${ }^{2}$ Adhiyamaan Arivazhagan \\ ${ }^{I}$ Faculty of Science, Engineering and Technology, Swinburne University of Technology, Melbourne, Australia \\ ${ }^{2}$ Department of Mechanical Engineering, PSG College of Technology, Coimbatore, India
}

\author{
Article history \\ Received: 01-06-2015 \\ Revised: $15-06-2015$ \\ Accepted: 24-06-2015 \\ Corresponding Author: \\ S.H. Masood \\ Faculty of Science, \\ Engineering and Technology, \\ Swinburne University of \\ Technology, Melbourne, \\ Australia \\ Email:smasood@swin.eduu
}

\begin{abstract}
Fused Deposition Modelling (FDM) has attained its reputation due to the capability of rapidly fabricating prototypes from concept design to real parts in shorter time and lower cost than traditional manufacturing processes. This study sheds light on the dynamic mechanical properties of Polyphenylsulfone (PPSF) material fabricated by FDM additive manufacturing process considering the effect of its various process parameters. Three major FDM process parameters are considered in this study, namely, raster angle, raster width and build style. Dynamic Mechanical Analysis is carried out with sweeping temperature at three different fixed frequencies, e.g., $1 \mathrm{~Hz}, 50 \mathrm{~Hz}$ and $100 \mathrm{~Hz}$. Taguchi method is employed for the optimization of process parameters towards achieving better damping properties. Experimental results such as maximum storage modulus, maximum loss modulus, peak of Tan Delta and maximum complex viscosity are captured and the effects of process parameters on these damping properties of PPSF samples are investigated.
\end{abstract}

Keywords: Fused Deposition Modelling, Dynamic Mechanical Analysis, PPSF, Process Parameters, Taguchi

\section{Introduction}

Additive Manufacturing (AM) is a group of technologies that creates three dimensional objects additively in a layer-by-layer manner. The origin of the concept of this technique can be traced back to early1890s and the development of which is closely tied with the development of the computer and software industry. The primary function of AM systems is to fabricate prototypes within a short period of time (usually within hours or days) to accelerate product development. Fused Deposition Modelling (FDM) developed by Stratasys Inc, is a filament based AM system, which offers the possibility of introducing new composite material for the FDM process as long as the new material can be made in feedstock filament form. FDM has a limited available range of thermoplastic materials such as Polycarbonate (PC), Acrylonitrile Butadiene Styrene (ABS), ULTEM and Polyphenylsulfone (PPSF) (Masood 2014).

Feedstock materials under processing in FDM undergo a series of known and unknown thermal and physical changes, which will finally affect the completed products' mechanical and damping properties (Masood and Song, 2005). With the help of Dynamic Mechanical Analysis, it is possible to study and investigate how and where such effects take place when FDM parts are subjected to cycling loading conditions. Similar valuable research works have already been done on PC, ABS and ULTEM materials. However limited research works have been carried out on products made with PPSF material used by FDM technology. PPSF is one kind of the engineering thermoplastics which offers excellent heat and chemical resistance and good mechanical properties (Stratasys, 2014).

Many research works have already been done previously considering the effect of FDM process parameters on the mechanical performance of parts made by different FDM materials. For example, Anitha et al. (2001) investigated how FDM process parameters affect the surface roughness of the finished ABS parts. They have chosen layer thickness, raster width and speed deposition as the process parameters. They used Taguchi method for the analysis and found that layer thickness has more significance among other process parameters. Lee et al. (2007) investigated the anisotropic compressive strength of FDM-processed ABS components considering the effect of various process 
parameters and compared with other AM systems. Bellini and Guceri (2003) have studied the effects different build orientations and build styles on the mechanical properties of FDM fabricated ABS test samples. Bagsik and Schoppner (2011) have investigated the influence of build orientation and tool path generation on the tensile properties of FDM processed ULTEM material. Sood et al. (2012) performed a comprehensive study to determine the most important Fused Deposition Modelling process parameters which have the significant effects on ABS prototypes. Based on the experimental results, they not only attained a glimpse into complex dependency of compressive stress on FDM process parameters, but also developed a statistically validated predictive equation, which was used to find optimal parameters combinations. Adhiyamaan and Masood (2012) have conducted an investigation on influence of main FDM process parameters on the dynamic mechanical properties of ABS material processed by FDM system. Adhiyamaan et al. (2014) have also conducted similar investigation on the ULTEM material processed by FDM. Domingo-Espin et al. (2014) have carried out study on influence of FDM nozzle diameter, number of contours and air gap on dynamic mechanical behaviour of Polycarbonate material.

PPSF thermoplastic materials have the highest heat and chemical resistance of all FDM materials. They are sterilisable and mechanically superior material with high strength and are ideal for applications in caustic and high heat environments (Novakova-Marcincinova, 2012). Very limited research work has been carried out on the performance of products made with PPSF material used by FDM technology.

This paper aims to investigate the dynamic mechanical properties of FDM fabricated PPSF samples with regard to three major FDM process parameters, namely, raster angle, raster width and build style.

\section{Fused Deposition Modelling}

The AM process can be categorized as liquid base, powder base or solid base, according to the types of raw materials used. The liquid-based AM process uses a light source to solidify the liquid polymer, layer by layer, in order to complete an AM product. The powder-based AM process is similar to the liquid-based AM, except that the raw material is replaced by powder and some of the light sources are replaced by a glue ejector. An advantage of the powder-based AM is that no support material is needed for fabricating the overhang feature as the powder itself can be the support. There are several different solid-based AM processes, one of which is fused deposition modelling (FDM) originally developed by Stratasys Inc.

The FDM process first fuses a solid thermoplastic filament drawn from a model material spool and then extrudes the fused material through a nozzle, as illustrated in Fig. 1, to form an AM product layer by layer. A support material spool is also used to deposit the support material for overhanging model features.

Some of the main components of the FDM machine are as follows (based on Fortus 900mc user guide).

\section{FDM Head}

Which liquefies the thermoplastic modeling material and extrudes it into precise layers that fuse to form the complete material.

\section{FDM Liquefier}

Used to melt the thermoplastic modeling material to an exact temperature to form the model. It is part of FDM head.

\section{FDM Tip}

Is the interchangeable extrusion nozzle at the bottom of FDM liquefier. The inside and outside diameter of tips determine the range of road widths and layer thickness. Both model and support material tips are available.

\section{Canister Bays}

Consists of model material bays and support material bays along with material drive block for supplying raw filament material into the FDM head.

\section{Material Drive Block}

Feeds filament from canister to liquefiers. Each canister bay has a drive lever to engage and disengage the drive block from canister. It contains sensors to communicate to system whether material is available to be loaded to liquefier.

There are various parameters that can be varied in Stratasys Fortus 900mc FDM machine. Some important parameters such as build style, raster angle and raster width are chosen for this study.

Build style is the raster pattern that the extruder follows and deposits the beads from nozzle onto part surface, layer by layer to fabricate the final products. It is determined by the air gap between the beads. One of the three patterns is called solid normal, which has no air gap existing between the beads as shown in the Fig. 1 . The build style sparse-double dense has small air gaps and the build style sparse has the maximum space of air gap as shown in the Fig. 3-4.

Raster width is the width of the bead deposited on a layer. It is determined by the FDM nozzle tip size. It can vary from $0.4064 \mathrm{~mm}$ to $0.8314 \mathrm{~mm}$ for the Fortus $900 \mathrm{mc}$ machine.

As depicted in the Fig. 1-3 raster angle is the angle of the beads deposited with respect to the $\mathrm{X}$ axis of the build table. The typical raster angles are $45^{\circ} / 45^{\circ}, 0^{\circ} / 90^{\circ}$ and $30^{\circ} / 60^{\circ}$. 


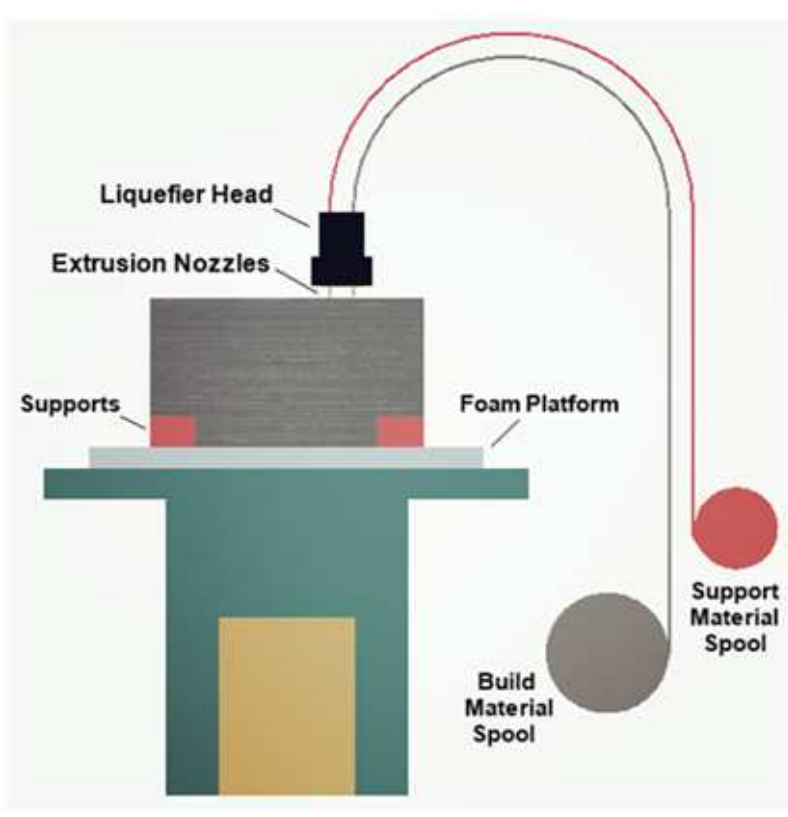

Fig. 1. Schematic of FDM process

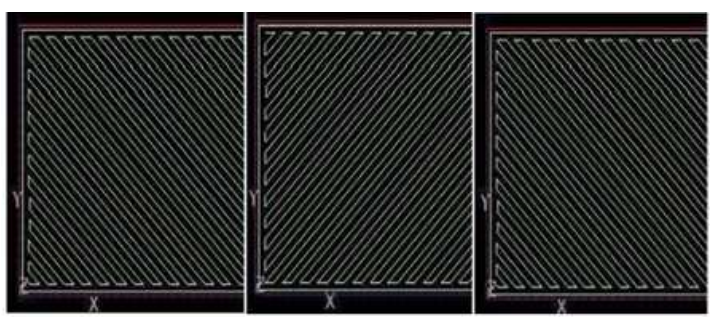

Fig. 2. Tool path for solid normal with raster angle $45^{\circ} / 45^{\circ}$
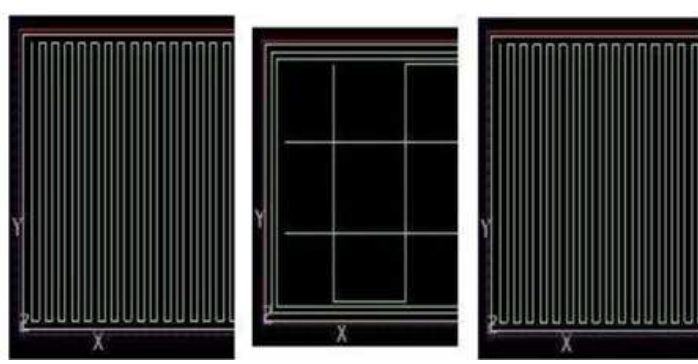

Fig. 3. Tool paths for sparse-double dense with raster angle $0^{\circ} / 90^{\circ}$

\section{Dynamic Mechanical Analysis}

Dynamic Mechanical Analysis (DMA) is a technique used to study and characterize materials by applying a small oscillatory force at a set frequency to the sample. This allows the materials response to stress, temperature, frequency and other values to be studied. DMA reports changes in stiffness and damping of the material. It can be used to investigate the viscoelastic behaviour of polymers. Within DMA process, a sinusoidal stress is applied on the specimen and the strain inside the material can be captured and measured.
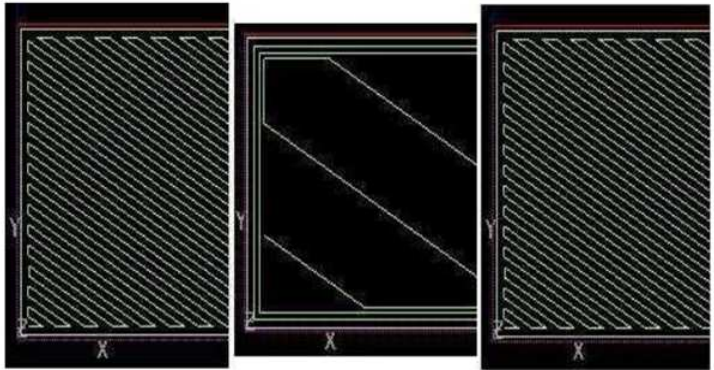

Fig. 4. Tool paths for sparse with raster angle $30^{\circ} / 60^{\circ}$

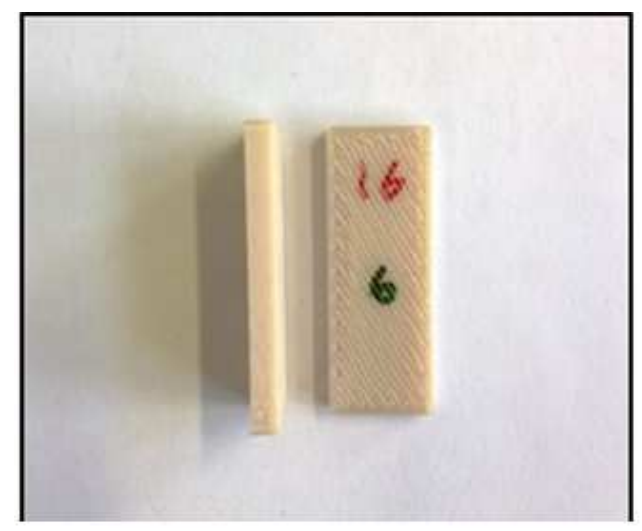

Fig. 5. PPSF samples made by FDM

This approach enables to investigate both molecular relaxation properties, i.e., loss modulus and mechanical or viscoelastic properties, i.e., complex viscosity of different materials encompassing several effects such as load, frequency and temperature all in one single measurement. DMA can sweep across frequency or temperature range. For frequency sweep, frequency can be varied from 0.01 to $100 \mathrm{~Hz}$ at a fixed temperature. For temperature sweep, instrument can change the temperature within experimental chamber from $-150^{\circ} \mathrm{C}$ to $600^{\circ} \mathrm{C}$ at a fixed frequency.

In this study, temperature sweep is employed. In DMA experiments, samples are subjected to three different fixed frequencies 1,50 and $100 \mathrm{~Hz}$ with constantly varying temperature ranged from around 25 to $270^{\circ} \mathrm{C}$.

\section{Taguchi Method}

Taguchi Method is widely employed in process design and product design, based on comprehensive experimental investigation. One of the most significant advantages of Taguchi Method is that it remarkably streamlines the experimental design and hence reduces the required time and costs. Without the necessity of carrying out numerous actual experiments and manual calculations, software like Minitab equipped with Taguchi analysis function is a very strong computational 
tool. It can perform swift and accurate evaluation on the discounted amount of experimental results. It uncovers the relationship between process parameters and part quality. Its analytical results provide guidance to determine the optimal combination of process parameters (Sood et al., 2009).

The process variables used in this study are build style, raster width and raster angle. The other possible influencing factors like temperature and humidity are viewed as stationary and not discussed in this analysis. Many previous researchers have already used this approach to analyse how process parameters affect part properties and got convincing results. Hence the authors believed the applicability of Taguchi method to optimize process parameter combinations. The Signal to Noise $(\mathrm{S} / \mathrm{N})$ ratio is calculated as follows:

$\mathrm{S} / \mathrm{N}$ ratio $=-10 * \log 10 * \mathrm{MSD}$

$\operatorname{MSD}=\sum\left(1 / \mathrm{y}^{2}\right) / \mathrm{n}$

where, ' $y$ ' is the property value of the sample.

\section{Experimental Setup}

The PPSF samples are fabricated using FORTUS $900 \mathrm{mc}$ with different FDM parameters. As mentioned before, in this study three different parameters (Build style, Raster Width and Raster Angle) are selected, each has three levels, as shown in Table 1. These experimental elements are the input to Minitab 16 software to compile a matrix in accordance with Taguchi Method design of three variables and three levels analysis. A total number of 27 samples were built in this sequence, as shown in Table 2.

Dynamic Mechanical Analysis experiments are carried out on all 27 PPSF samples on TA Instruments
DMA 2980. It has a versatile sample clamp system fit for various geometries. Besides, it also offers a broad range of deformation modes (single/dual cantilever, 3 point bend, shear sandwich, compression and tension).

The dimensions of the rectangular PPSF experimental samples fabricated by FDM machine used in this study are: Length $35 \mathrm{~mm}$, Width $12.7 \mathrm{~mm}$ and Thickness $3.2 \mathrm{~mm}$. Single cantilever deformation mode of DMA 2980 is chosen. Fig. 5 shows some of the PPSF samples made by FDM.

\section{Results}

Once all the laboratory based experiments are completed, experimental results are captured and recorded by Thermal Advantage Universal Analysis Software. Based on the data collected, tables and a number of bar charts are developed. Thermal Advantage Universal Analysis software offers a great convenience for users to plot custom graphs. Three different trajectories will be plotted in overlapping manner. The $\mathrm{X}$ axis is selected as temperature in ${ }^{\circ} \mathrm{C}$ and $\mathrm{Y}$ axis can be selected as storage modulus (MPa), Loss modulus (MPa), complex viscosity $\left(\mathrm{MPa}^{*} \mathrm{Sec}\right)$ in any combinations. Such overlaid graphs for temperature scans for solid normal samples are shown in the Fig. 6-7.

Figure 6 illustrates the overlapping trajectories of Loss Modulus and Tan Delta signals of solid normal samples. It is clear that although the values of different samples varied, the trends are quite similar. Fig. 7 illustrates the graph of overlapping trajectories of Storage Modulus and Complex Viscosity signals of solid normal samples. Similar overlapping graphs were generated for sparse and sparse double dense samples.

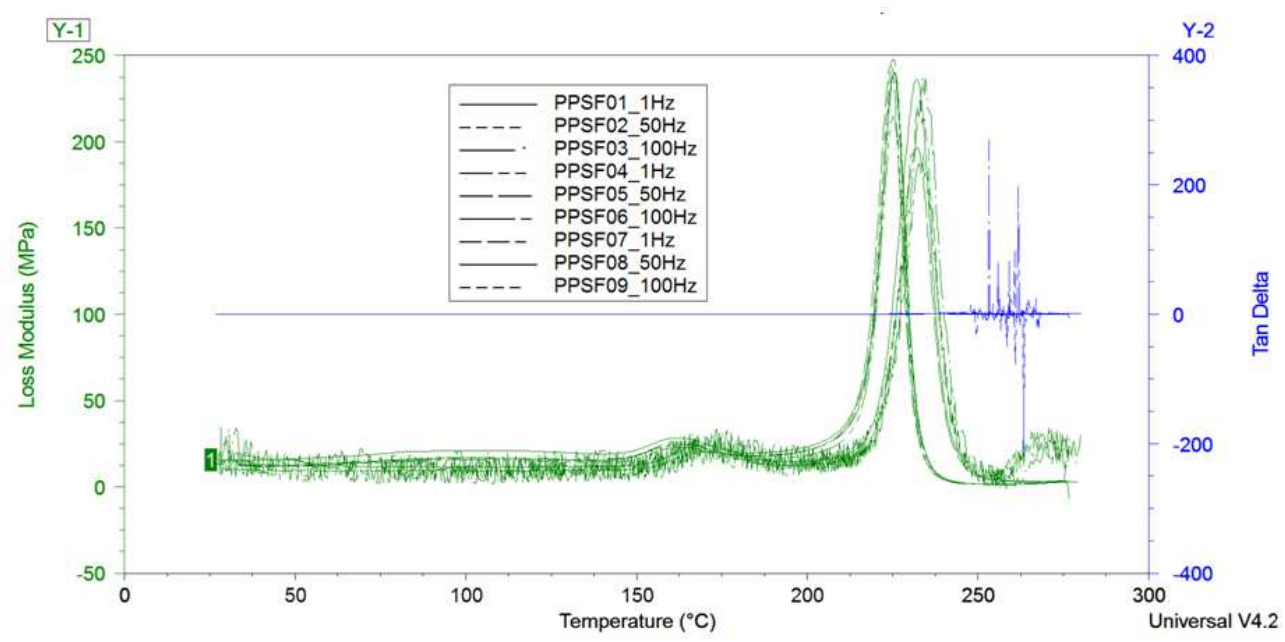

Fig. 6. Temperature scan graph of storage modulus, loss modulus and tan delta of PPSF samples at three different frequencies -solid normal samples 


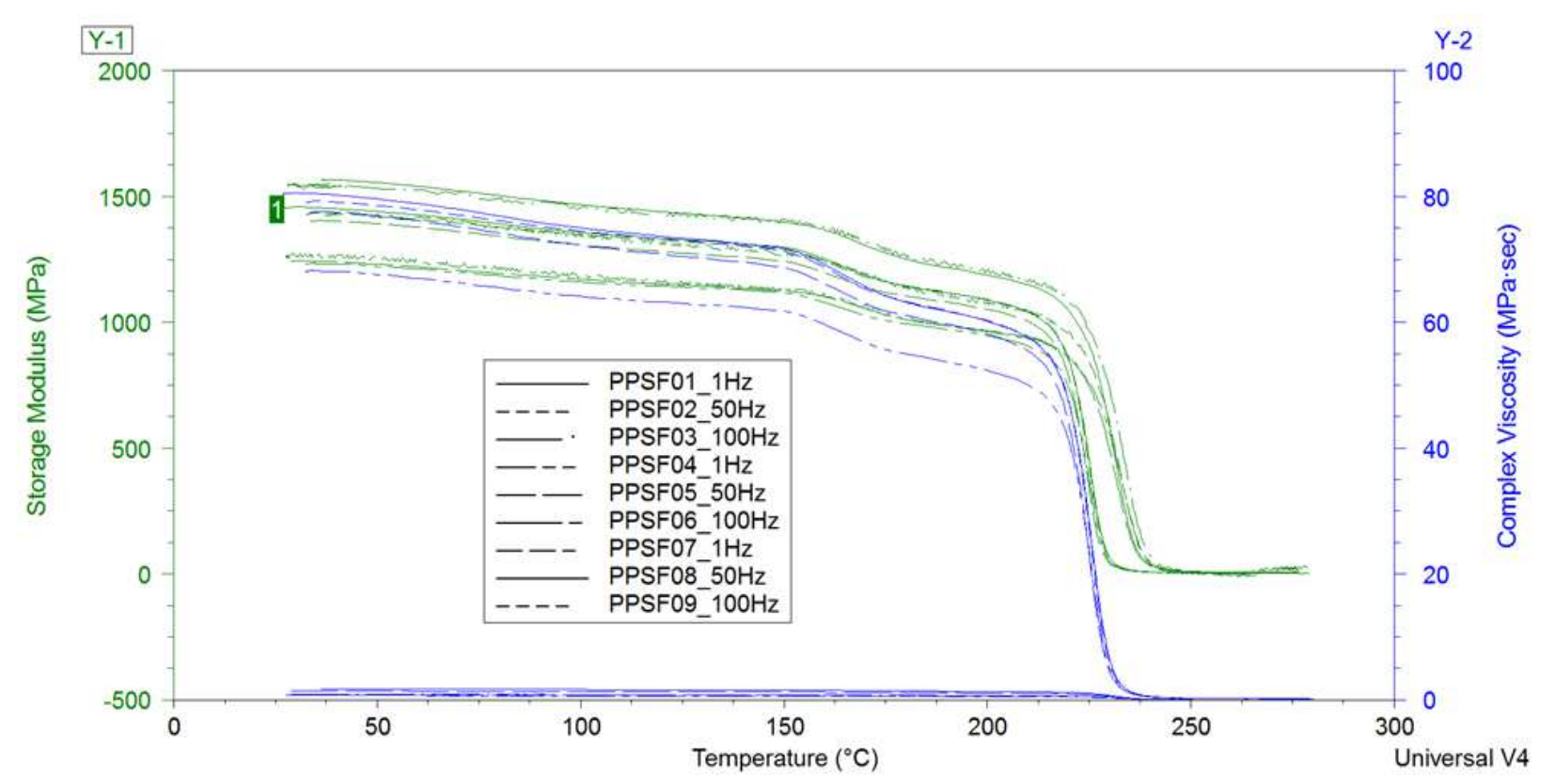

Fig. 7. Temperature scan graph of complex viscosity and flexural modulus of PPSF samples at three different frequenciessolid normal samples

Table 1. List of FDM parameters used for fabrication of PPSF experimental samples

\begin{tabular}{|c|c|c|c|c|}
\hline Parameter number & Parameters & Level 1 & Level 2 & Level 3 \\
\hline 1 & Build style & Solid normal & Sparse-double dense & Sparse \\
\hline 2 & Raster width (T16 tip size) & $0.406 \mathrm{~mm}$ & $0.606 \mathrm{~mm}$ & $0.781 \mathrm{~mm}$ \\
\hline 3 & Raster angle & $30^{\circ} / 60^{\circ}$ & $45^{\circ} / 45^{\circ}$ & $0^{\circ} / 90^{\circ}$ \\
\hline
\end{tabular}

Table 2. Details of fabrication parameters of all experimental samples

\begin{tabular}{lllll}
\hline Batch No. & Build style & Raster width (T16) & Raster angle & Sample numbers \\
\hline 1 & Solid normal & 0.406 & $30^{\circ} / 60^{\circ}$ & $1,2,3$ \\
2 & Solid normal & 0.606 & $45^{\circ} / 45^{\circ}$ & $4,5,6$ \\
3 & Solid normal & 0.781 & $0^{\circ} / 90^{\circ}$ & $7,8,9$ \\
4 & Sparse-double dense & 0.406 & $45^{\circ} / 45^{\circ}$ & $10,11,12$ \\
5 & Sparse-double dense & 0.606 & $0^{\circ} / 90^{\circ}$ & $13,14,15$ \\
6 & Sparse-double dense & 0.781 & $30^{\circ} / 60^{\circ}$ & $16,17,18$ \\
7 & Sparse & 0.406 & $0^{\circ} / 90^{\circ}$ & $19,20,21$ \\
8 & Sparse & 0.606 & $30^{\circ} / 60^{\circ}$ & $22,23,24$ \\
9 & Sparse & 0.781 & $45^{\circ} / 45^{\circ}$ & $25,26,27$ \\
\hline
\end{tabular}

Table 3. Property values of PPSF samples for solid normal build style

\begin{tabular}{|c|c|c|c|c|c|c|c|c|c|}
\hline $\begin{array}{l}\text { Sample } \\
\text { Number }\end{array}$ & $\begin{array}{l}\text { Frequency } \\
(\mathrm{Hz})\end{array}$ & $\begin{array}{l}\text { Raster } \\
\text { Width } \\
\text { (T16) }\end{array}$ & $\begin{array}{l}\text { Raster } \\
\text { Angle }\end{array}$ & $\begin{array}{l}\text { Max } \\
\text { Storage } \\
\text { Modulus } \\
(\mathrm{MPa})\end{array}$ & $\begin{array}{l}\text { Max } \\
\text { Loss } \\
\text { Modulus } \\
(\mathrm{MPa})\end{array}$ & $\begin{array}{l}\text { Peak of } \\
\text { Tan } \\
\text { Delta }\end{array}$ & $\operatorname{Tg}\left({ }^{\circ} \mathrm{C}\right)$ & $\begin{array}{l}\text { Max } \\
\text { Flexural } \\
\text { Modulus } \\
(\mathrm{MPa})\end{array}$ & $\begin{array}{l}\text { Max } \\
\text { Complex } \\
\text { Viscosity } \\
\left(\mathrm{MPa}^{*} \mathrm{sec}\right)\end{array}$ \\
\hline 1 & 1 & 0.406 & $30^{\circ} / 60^{\circ}$ & 1458 & 239.3 & 1.531 & 231.26 & 1458 & 80.530 \\
\hline 2 & 50 & 0.406 & $30^{\circ} / 60^{\circ}$ & 1435 & 247.7 & 1.540 & 230.75 & 1434 & 1.5910 \\
\hline 3 & 100 & 0.406 & $30^{\circ} / 60^{\circ}$ & 1551 & 236 & 157.400 & 253.36 & 1555 & 0.8593 \\
\hline 4 & 1 & 0.606 & $45^{\circ} / 45^{\circ}$ & 1236 & 214.4 & 1.497 & 230.50 & 1234 & 68.3000 \\
\hline 5 & 50 & 0.606 & $45^{\circ} / 45^{\circ}$ & 1244 & 196.2 & 1.482 & 239.04 & 1244 & 1.3750 \\
\hline 6 & 100 & 0.606 & $45^{\circ} / 45^{\circ}$ & 1272 & 189.7 & 190.400 & 261.90 & 1271 & 0.7029 \\
\hline 7 & 1 & 0.781 & $0^{\circ} / 90^{\circ}$ & 1404 & 244 & 1.563 & 230.25 & 1404 & 77.6200 \\
\hline 8 & 50 & 0.781 & $0^{\circ} / 90^{\circ}$ & 1568 & 236.1 & 1.475 & 239.04 & 1568 & 1.7320 \\
\hline 9 & 100 & 0.781 & $0^{\circ} / 90^{\circ}$ & 1439 & 223.6 & 82.3200 & 260.64 & 1439 & 0.7950 \\
\hline
\end{tabular}


As shown in Fig. 6-7, in all the cases, the storage modulus decreases with increase in temperature and loss modulus value increases. In a similar way the complex viscosity decreases with increase in temperature at constant frequency.

Table 3 shows the maximum property values of solid normal samples in which SN denotes solid normal. Similar values are obtained for sparse and sparse double dense samples. All these data are given as input to the Taguchi analysis and the response tables for 'mean' are generated.

\section{Discussion}

Experimental values obtained are compared with bar charts and illustrated in the following sections.

Figure 8 delineates that sample number 8 , with raster angle $0^{\circ} / 90^{\circ}$ and raster width $0.781 \mathrm{~mm}$, attained the highest storage modulus of $1568 \mathrm{MPa}$ when subjected to a frequency of $50 \mathrm{~Hz}$. For the same frequency, the combination of raster width and raster angle of 0.781 $\mathrm{mm}$ and $0^{\circ} / 90^{\circ}$, as well as $0.406 \mathrm{~mm}$ and $30^{\circ} / 60^{\circ}$ yields higher moduli. When compared among themselves the values are close enough. But the combination of raster width $0.606 \mathrm{~mm}$ and $45^{\circ} / 45^{\circ}$ yields low values. It can be concluded that samples made by FDM parameters of raster angle $0^{\circ} / 90^{\circ}$ and raster width $0.781 \mathrm{~mm}$ have the highest maximum storage modulus. The property value increases as the frequency increases.

Figure 9 highlights that sample number 2, with raster angle $30^{\circ} / 60^{\circ}$ and raster width $0.406 \mathrm{~mm}$ attained the highest value of $247.7 \mathrm{MPa}$ when subjected to frequency $50 \mathrm{~Hz}$. This graph illustrates that the combination of raster angle $30^{\circ} / 60^{\circ}$ and raster width $0.406 \mathrm{~mm}$ attained the highest loss modulus value except for 1 $\mathrm{Hz}$ of frequency, in which sample number 7 with raster angle $0^{\circ} / 90^{\circ}$ and raster width $0.781 \mathrm{~mm}$ yields higher value. Again the combination of raster angle $45^{\circ} / 45^{\circ}$ and raster width $0.606 \mathrm{~mm}$ attained the lowest maximum loss modulus value.

Figure 10 reveals that for peak of Tan Delta the combination of raster angle $45^{\circ} / 45^{\circ}$ and raster width $0.606 \mathrm{~mm}$ attained the highest value of 190.4 when subjected to the frequency of $100 \mathrm{~Hz}$. The combination of raster angle $30^{\circ} / 60^{\circ}$ and raster width $0.406 \mathrm{~mm}$ has the second highest and the combination of raster angle $0^{\circ} / 90^{\circ}$ and raster width $0.781 \mathrm{~mm}$ has the smallest value, both for a frequency of $100 \mathrm{~Hz}$. It is also remarkable that the experiments performed at 1 $\mathrm{Hz}$ and $50 \mathrm{~Hz}$ of frequency have attained very low peak of Tan Delta value.

Figure 11 interprets that sample number 6 fabricated with raster angle $45^{\circ} / 45^{\circ}$ and raster width $0.606 \mathrm{~mm}$ attained the highest glass transition temperature value of $261.9^{\circ} \mathrm{C}$ when subjected to $100 \mathrm{~Hz}$ of frequency. From this graph it is obvious that for the same fabrication parameters, samples attained higher glass transition temperature with the increase of frequency.

Figure 12 depicts that sample number 1 with raster angle $30^{\circ} / 60^{\circ}$ and raster width $0.406 \mathrm{~mm}$ yields the highest maximum complex viscosity value of 80.53 $\mathrm{MPa}^{*} \mathrm{sec}$ when subjected to $1 \mathrm{~Hz}$ of frequency. While the combination of raster angle $0^{\circ} / 90^{\circ}$ and raster width $0.781 \mathrm{~mm}$ are close to the previous one, the combination of raster angle $45^{\circ} / 45^{\circ}$ and raster width $0.606 \mathrm{~mm}$ attained the lowest. Here, as the frequency increases the complex viscosity drastically decreases. Similar graphs are plotted for sparse and sparse double dense samples and almost similar trends were seen in those samples also. All these values are given as input for the Minitab software and Taguchi analysis are carried out.

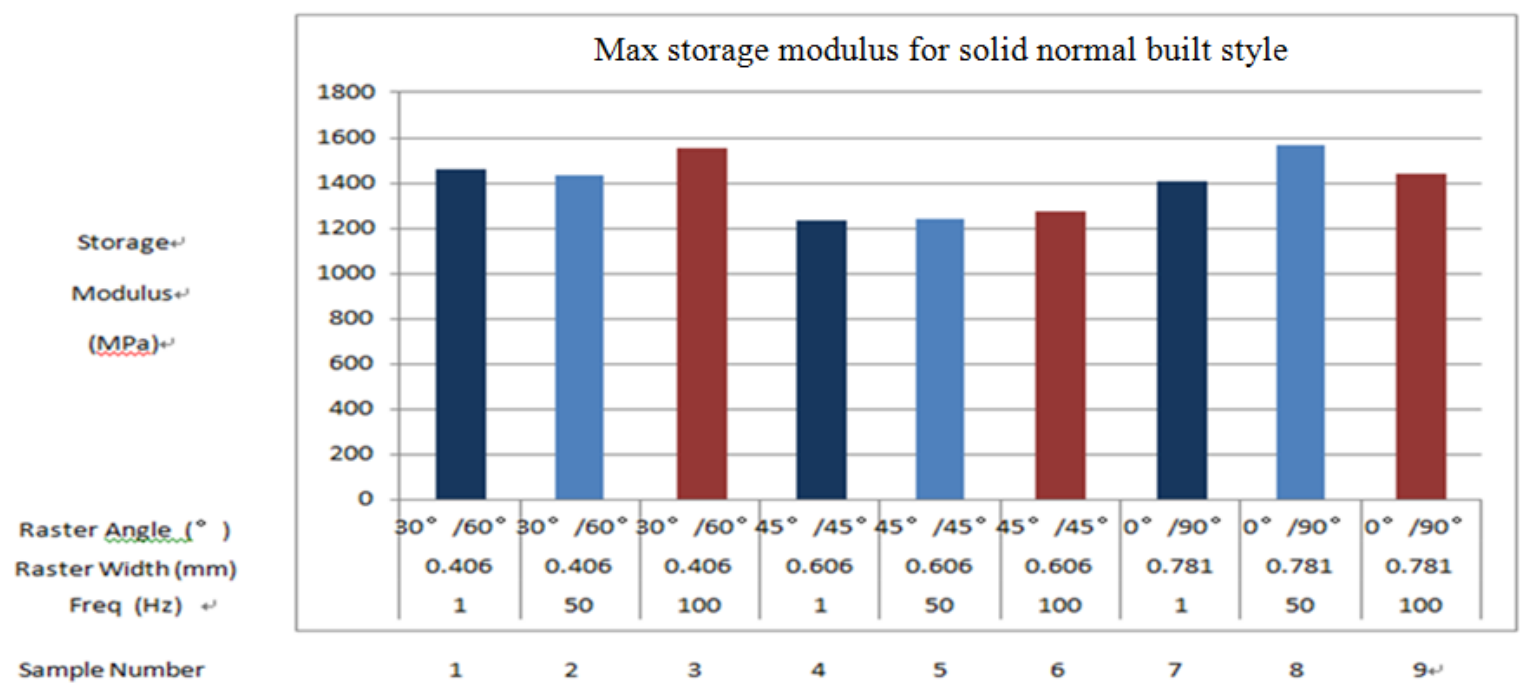

Fig. 8. Max storage modulus for solid normal build style 


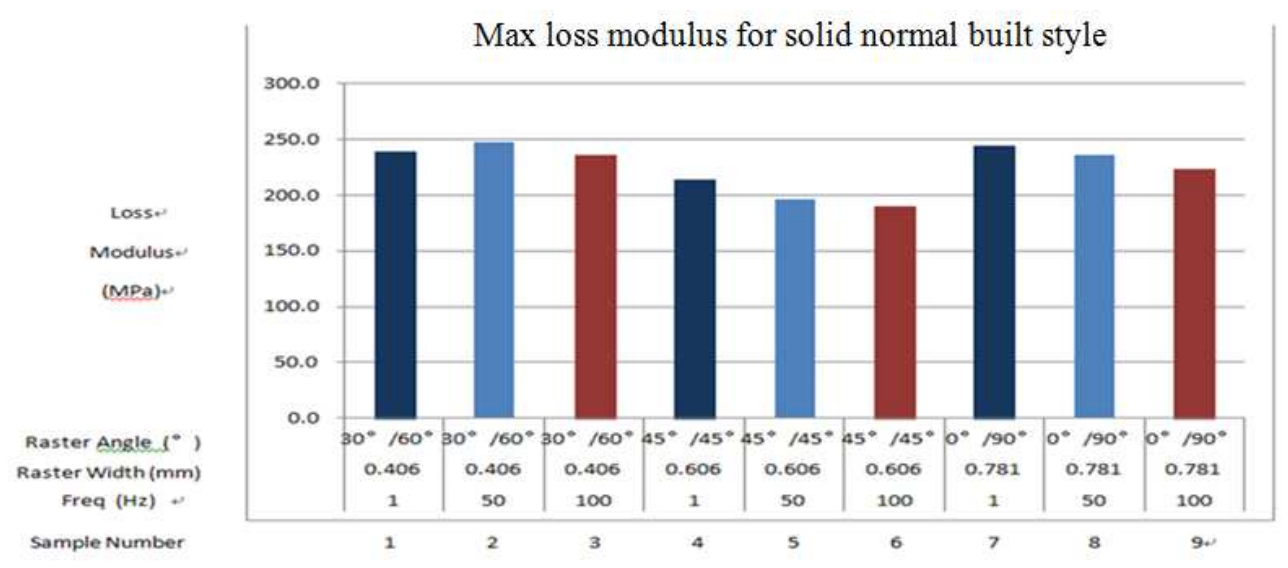

Fig. 9. Max loss modulus for solid normal build style

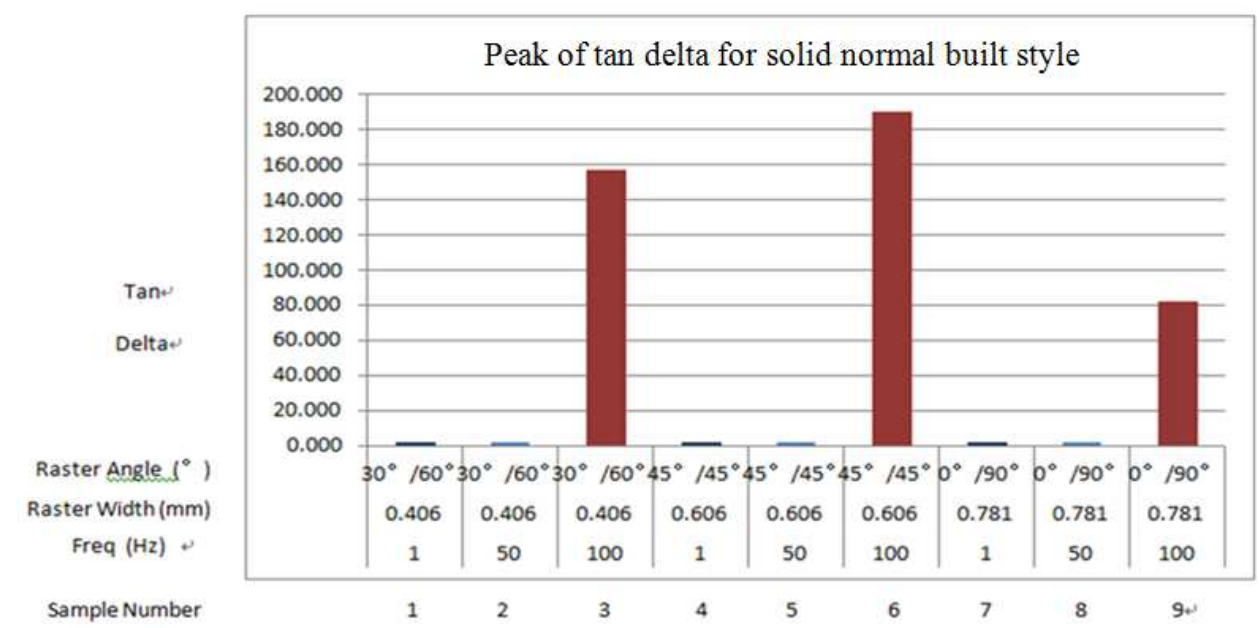

Fig. 10. Peak of tan delta for solid normal build style

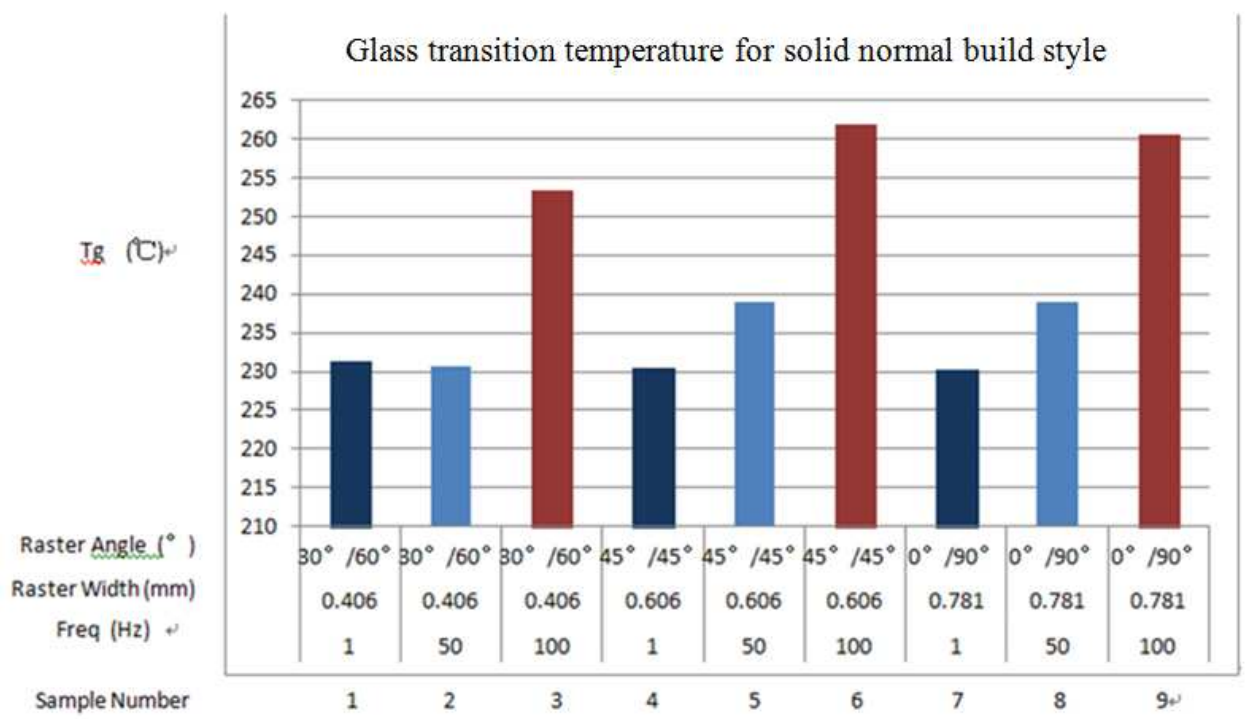

Fig. 11. Glass transition temperature for solid normal build style 


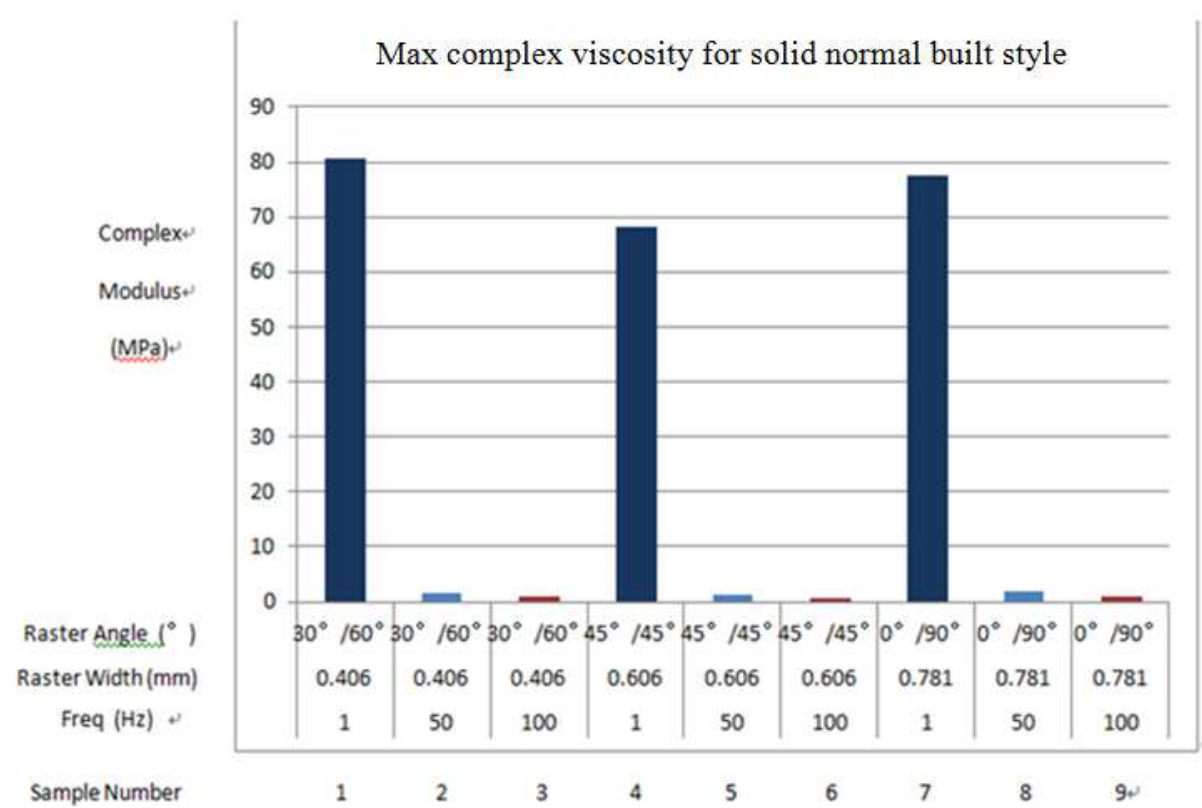

Fig. 12. Max complex viscosity for solid normal build style

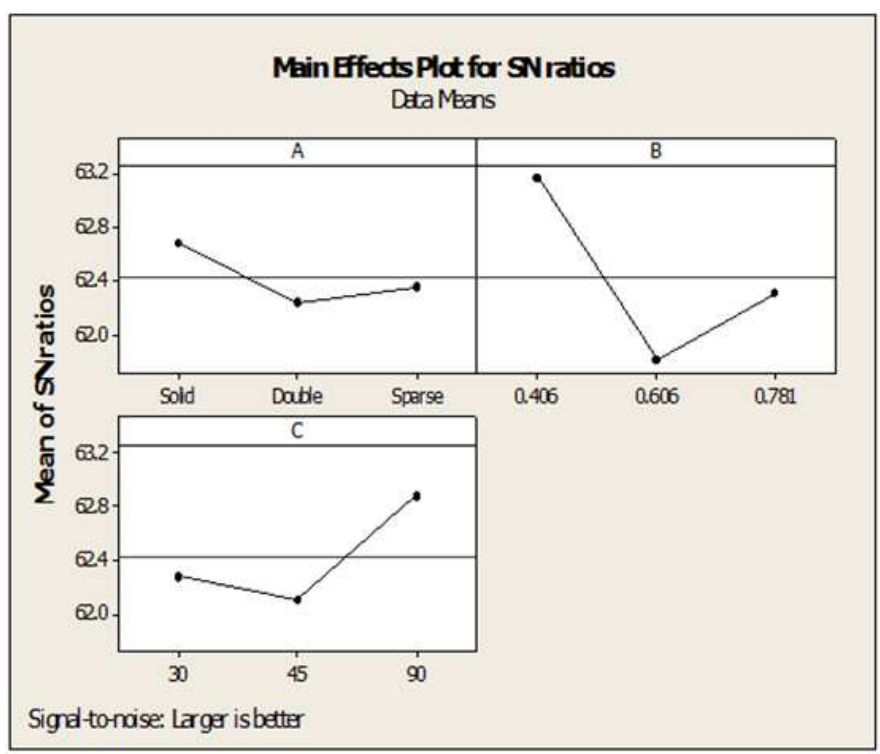

Fig. 13. Response table for $\mathrm{S} / \mathrm{N}$ ratios

The process variables used in this study are build style (A), raster width (B) and raster angle (C). The orthogonal array chosen in Taguchi design for this study is L9 $\left(3^{3}\right)$. This array consists of 3 columns for assigning process variables and 9 rows for designating experimental conditions as shown in Table 4. The last column $\mathrm{R}$ in Table 4 is for inputting response data, which in this case represents the modulus values recorded from experiments.

With all these data the $\mathrm{S} / \mathrm{N}$ ratio is calculated and the response table for various levels are generated as shown in Table 5.
The Response table for 'Means' obtained is listed in Table 6.

Table 4, 5 and Fig 13 and 14 suggest that the optimum combination of FDM process parameters to attain maximum storage modulus when subjected to Frequency of $1 \mathrm{~Hz}$ is Solid Normal build style, raster width at $0406 \mathrm{~mm}$ and with raster angle $0^{\circ} / 90^{\circ}$. This is because the solid normal build style has fewer air gaps when compared to other build styles sparse and sparse double-dense.

In the same approach, Taguchi analysis was used to determine the optimal FDM process combinations 
for storage modulus when subjected to frequencies of $50 \mathrm{~Hz}$ and $100 \mathrm{~Hz}$, as well as the other five investigated properties, each exposed to three different frequencies. A total number of 18 analyses were carried out.

Considering the Maximum Storage Modulus of FDM built PPSF samples, it is predicted that, when subjected to a frequency of $1 \mathrm{~Hz}$, the combination of process parameters, namely, Solid Normal build style, Raster Width at $0.606 \mathrm{~mm}$ and Raster Angle of $0^{\circ} / 90^{\circ}$ resulted in higher values. When subjected to frequency of 50 and $100 \mathrm{~Hz}$, the predictions are identical, with the combination of Solid Normal build style, Raster Width $0.406 \mathrm{~mm}$ and Raster Angle of $0^{\circ} / 90^{\circ}$.

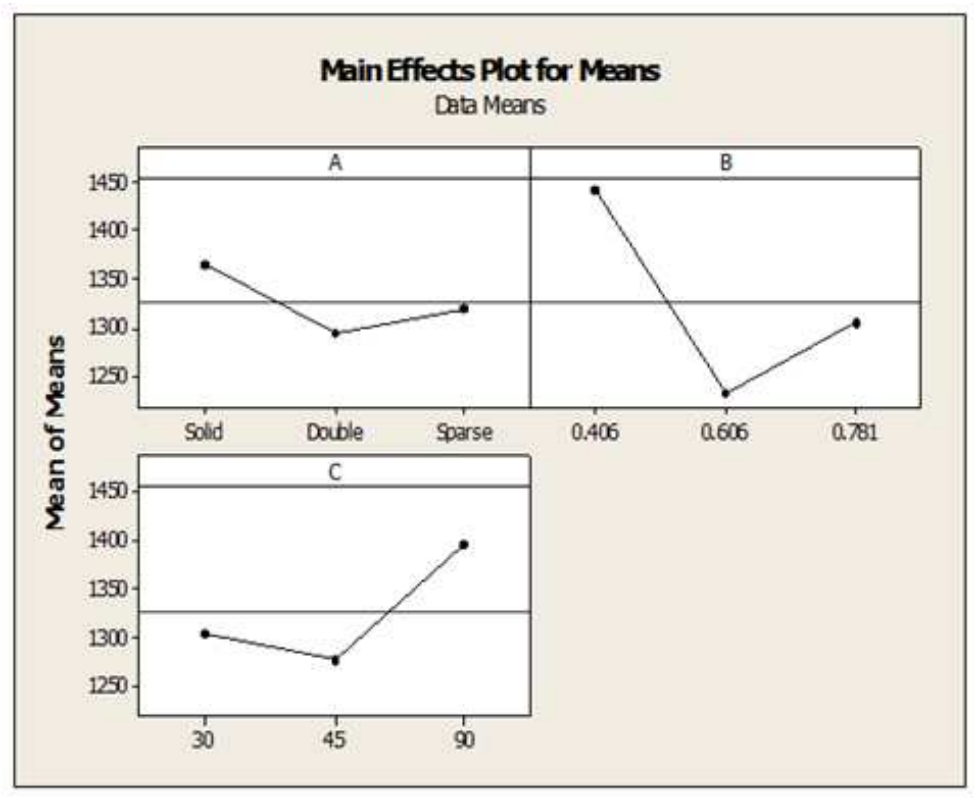

Fig. 14. Response table for means

Table 4. Taguchi design matrix of 9 samples which were subjected to Frequency $1 \mathrm{~Hz}$

\begin{tabular}{llll}
\hline A & B & C & R1 \\
\hline Solid normal & 0.406 & 30 & 1458 \\
Solid normal & 0.606 & 45 & 1236 \\
Solid normal & 0.781 & 90 & 1404 \\
Sparse-double dense & 0.406 & 45 & 1348 \\
Sparse-double dense & 0.606 & 90 & 1268 \\
Sparse-double dense & 0.781 & 30 & 1266 \\
Sparse & 0.406 & 90 & 1521 \\
Sparse & 0.606 & 30 & 1191 \\
Sparse & 0.781 & 45 & 1247 \\
\hline
\end{tabular}

Table 5. Response table for $\mathrm{S} / \mathrm{N}$ ratios

\begin{tabular}{lllr}
\hline Level & A & B & C \\
\hline 1 & 62.69 & 63.17 & 62.28 \\
2 & 62.23 & 61.81 & 62.12 \\
3 & 62.36 & 62.30 & 62.88 \\
Delta & 0.45 & 1.36 & 0.77 \\
Rank & 3.00 & 1.00 & 2.00 \\
\hline & & & $\mathrm{C}$ \\
Table 6. Response table for means & $\mathrm{A}$ & $\mathrm{B}$ & 1305 \\
\hline Level & 1366 & 1442 & 1277 \\
\hline 1 & 1294 & 1232 & 1398 \\
2 & 1320 & 211 & 121 \\
3 & 72 & 1 & 2 \\
Delta & 3 & & 1306 \\
Rank & & 12 & \\
\hline
\end{tabular}


Table 7. Predicted optimum combination of FDM process parameters by Taguchi analysis

\begin{tabular}{lllll}
\hline Item & Frequency $(\mathrm{Hz})$ & Build style & Raster width $(\mathrm{mm})$ & Raster angle \\
\hline \multirow{2}{*}{ Max storage modulus (MPa) } & 1 & Solid normal & 0.606 & $0^{\circ} / 90^{\circ}$ \\
& 50 & Solid normal & 0.406 & $0^{\circ} / 90^{\circ}$ \\
Max loss modulus (MPa) & 100 & Solid normal & 0.406 & $0^{\circ} / 90^{\circ}$ \\
& 1 & Sparse & 0.406 & $0^{\circ} / 90^{\circ}$ \\
Peak of tan delta & 50 & Solid normal & 0.406 & $0^{\circ} / 90^{\circ}$ \\
& 100 & Solid normal & 0.406 & $0^{\circ} / 90^{\circ}$ \\
& 1 & Sparse & 0.406 & $0^{\circ} / 90^{\circ}$ \\
Glass transition temp Tg $\left({ }^{\circ} \mathrm{C}\right)$ & 50 & Solid normal & 0.406 & $30^{\circ} / 60^{\circ}$ \\
& 100 & Sparse & 0.781 & $45^{\circ} / 45^{\circ}$ \\
Max complex viscosity $\left(\mathrm{MPa}{ }^{*} \mathrm{sec}\right)$ & 1 & Sparse & 0.406 & $0^{\circ} / 90^{\circ}$ \\
& 50 & Sparse-double dense & 0.781 & $0^{\circ} / 90^{\circ}$ \\
& 100 & Sparse & 0.606 & $45^{\circ} / 45^{\circ}$ \\
\hline
\end{tabular}

Table 7 shows the predicted optimum combination of FDM process parameters for all the properties by Taguchi analysis. For the other properties, the predicted results can also be interpreted in the same way as interpreted for storage modulus.

\section{Conclusion}

This paper mainly focused on the dynamic mechanical properties of PPSF samples fabricated by FDM technology and investigated how the process parameters affect these properties.

In dynamic mechanical analysis, this study compared and discussed the experimental data obtained in temperature sweep. From the results it is clear that for PPSF samples built in solid normal, sparse and sparse double dense style, the raster width $0.406 \mathrm{~mm}$, no matter which raster angle it was used with, attained the highest storage modulus values than the other combinations. For the loss modulus, the result is the same, as parameter combinations containing raster width $0.406 \mathrm{~mm}$ helped achieved better performance.

Peak of Tan Delta, as it is a ratio of viscous to elastic response, which is the ratio of loss modulus to storage modulus, varied for different samples. For glass transition temperature, the results show that when subjected to $1 \mathrm{~Hz}$ of frequency, all the samples attained maximum values around $230^{\circ} \mathrm{C}$. As the frequency increased, samples performed differently and became less predictable. For both storage modulus and complex viscosity, the better raster width parameter is again $0.406 \mathrm{~mm}$, no matter which raster angle is used.

In Taguchi analysis, the experimental data obtained in DMA process are used in determining the optimum FDM process parameter combination for achieving better dynamic mechanical properties of built samples. According to these results, in almost all cases, the build style parameter solid normal along with raster width $0.406 \mathrm{~mm}$ yields good results.
All in all, it can be concluded that build style solid normal and raster width $0.406 \mathrm{~mm}$ are the most influencing parameters of dynamic mechanical properties of PPSF samples.

\section{Acknowledgement}

This project is a joint research work of PSG College of Technology, Coimbatore, Tamil Nadu, India and Swinburne University of Technology, Melbourne, Australia. Samples of PPSF material were fabricated at Stratasys Fortus 900mc Fused Deposition Modelling machine at PSG College of Technology. Experiments were all conducted with the use of DMA 2980 equipment at Swinburne University of Technology. Authors also acknowledge the advice provided by $\mathrm{Mr}$ Omar Ahmed Mohamed of Swinburne University in the design of experiments.

\section{Author's Contributions}

Bolin Huang: Conducted all the DMA tests and design of experiments and wrote the initial draft of the paper.

S.H. Masood: Supervised and guided the whole research work and revised and improved the final drafts of the paper.

Mostafa Nikzad: Supervised the experimental DMA work and revised the figures and tables.

Prabhu Raja Venugopal: Provided guidance on the design and fabrication of FDM samples used in the DMA tests.

Adhiyamaan Arivazhagan: Contributed in substantial revision and improvement of the first draft of the paper and in design and fabrication of FDM test samples.

\section{Ethics}

All authors have read and approved the publication of this article. There are no ethical issues arising out of the publication of this paper. 


\section{References}

Adhiyamaan, A. and S.H. Masood, 2012. Dynamic mechanical properties of ABS material processed by fused deposition modelling. Int. J. Eng. Res. Applications 2: 2009-2014.

Adhiyamaan, A., A. Saleem, S.H. Masood, M. Nikzad and K.A. Jagadeesh, 2014. Study of dynamic mechanical properties of fused deposition modelling processed ULTEM material. Am. J. Eng. Applied Sci., 7: 304-312.

Anitha, R., S. Arunachalam and P. Radhakrishnan, 2001. Critical parameters influencing the quality of prototypes in fused deposition modelling. J. Mater. Process. Technol.. 118: 385-388. DOI: 10.1016/S0924-0136(01)00980-3

Bagsik, A. and V. Schoppner, 2011. Mechanical properties of fused deposition modelling parts manufactured with Ultem*9085. Proceedings of the Annual Technical Conference, Soc. Plastics Engineers, (ANTEC, 2011), Boston, MA, pp: 1294-1298.

Bellini, A. and S. Guceri, 2004. Mechanical characterisation of parts fabricated using fused deposition modelling. Rapid Prototyping J., 9: 252-264.

Domingo-Espin, M., S. Borros, N. Agullo, A-A. GarciaGranada and G. Reyes, 2014. Influence of building parameters on the dynamic mechanical properties of polycarbonate fused deposition modelling parts. 3D Printing, 1: 70-77.

Lee, C.S., S.G. Kim, H.J. Kim and S.H. Ahn, 2007. Measurement of anisotropic compressive strength of rapid prototyping parts. J. Mater. Process. Technol., 187-188: 627-630.

DOI: $10.1016 /$ j.jmatprotec.2006.11.095
Masood, S.H., 2014. Advances in Fused Deposition Modelling, In: Advances in Additive Manufacturing and Tooling, Masood, S.H., (Eds.), Comprehensive Materials Processing, Science Direct, Elsevier, pp: 69-91.

Masood, S.H. and W.Q. Song, 2005. Thermal characteristics of a new metal/polymer material for FDM rapid prototyping process. Assembly Automation, 25: 309-315. DOI: $10.1108 / 01445150510626451$

Novakova-Marcincinova, L. and I. Kuric, 2012. Basic and advanced materials for fused deposition modeling rapid prototyping technology. Manuf. Ind. Eng., 11: 24-27.

Sood, A.K., R.K. Ohdar and S.S. Mahapatra, 2012. Experimental investigation and empirical modelling of FDM process for compressive strength improvement. J. Advanced Res., 3: 81-90. DOI: $10.1016 /$ j.jare.2011.05.001

Sood, A.K., R.K. Ohdar and S.S. Mahapatra, 2009. Improving dimensional accuracy of fused deposition modelling processed part using grey Taguchi method. Materials Design, 30: 4243-4252. DOI: 10.1016/j.matdes.2009.04.030

Stratasys, 2014, 3D PPSF/PPSU: 3D print heat-resistant, strong sterilizable parts. 